\title{
Student Evaluations and the Performance of University Teaching: Teaching to the Test
}

John L. Hoben, Cecile Badenhorst, and Sarah Pickett

\begin{abstract}
What do course evaluation questionnaires (CEQs) do to our teaching and to our perceptions of ourselves as teachers? We are all early- to mid-career academics at a midsized Canadian university who explore how course evaluation questionnaires have affected our academic identities. By using autoethnography and critical reflection, we examine how CEQs shape and restrict our teaching identities as well as the identities of our students. Alternative ways of assessing teaching excellence and promoting communities of inquiry are explored.
\end{abstract}

\section{Background}

The course evaluation questionnaires (CEQs) are a common source of evidence to assess faculty performance in teaching. CEQs are most often administered by central units within the university and are constructed around a universalized set of questions that can be used across disciplines. The development of questions and compilation of the responses takes place at a distance from the individual teacher. Students respond anonymously and usually have to answer survey-type questions with space being provided for open-ended responses as well. Instructors receive CEQ reports once the data is compiled and these reports are used in promotion and tenure processes as proof of teaching effectiveness. Although assessing teaching is an important goal, one of the central issues with the current CEQs regimes, is that it presents a service delivery model of teaching and learning, as opposed to a more dialogical and contextualized picture of the classroom environment.

More troubling, only the teachers are assessed even though classrooms are a microcosm of the institutional forces, personalities, and cultures that intersect within these spaces. Within this model, it is easy for student satisfaction to take precedence over pedagogic goals. Feeling frustrated with this form of teaching evaluation and wondering what effect this type of assessment had on our teaching, led us to this paper. Butler (1997) shows we perform our identities through repeated acts. We draw on identity-categories that are largely external to us, and over time with much repetition we create a sense of individual identity. Performing teaching is a large part of the construction of our academic subjectivities, particularly for those of us in Education faculties. Performing the effective teacher is important to us, since we value strong pedagogic design and student engagement. The question we ask ourselves is: What do CEQs do to our teaching and to our perceptions of ourselves as teachers? 
John L. Hoben, Cecile Badenhorst, and Sarah Pickett

\section{Course Evaluation Questionnaires}

The extensive literature on CEQs highlights the contentious nature of these evaluations. There is a continual stream of research that maintains that CEQs are a valued form of assessing teaching effectiveness. Winer, DiGenova, Costopoulos, and Cardoso (2016), for example, found CEQs to be unbiased and reliable. However, much of the literature is critical and revolves around the validity of student respondents. This research suggests that when it comes to student respondents, there are many flaws in the CEQ process. For example, many studies suggest that low levels of participation by students, particularly with online evaluation forms, provide biased results (Groen \& Herry, 2017). Certain students are more likely to complete the forms, and these tend to be female and/or academically strong students or students who receive high grades in the course (Adams \& Umbach, 2012). Some studies have suggested that students grade professors higher if they get good grades and lower if they get poor grades (Maurer, 2006). Zumbach and Funke (2014) even found that mood was a factor in CEQ responses. When students were manipulated into a positive mood, they rated professors more highly than those in a negative mood. Some studies argue that only students with extreme opinions respond to course evaluations which provide dichotomized responses, while others raise concerns about gender bias. MacNell, Driscoll, and Hunt (2015) found that both male and female students rate male professors higher. Male students particularly rated female professors lower.

Other studies note that students often lack motivation to fully complete the forms and rush through it without paying much attention. In Bassett, Cleveland, Acorn, Nix, and Snyder's (2017) study, "catch questions" were embedded into the CEQ, for example, "The instructor was late or absent for all class meetings" (p. 435). If students responded, "definitely true" or "more true than false," they were deemed to be making an insufficient effort to respond to the CEQ. Results demonstrated one out of four students showed insufficient effort at responding to CEQs. This study also showed that students sometimes take CEQs seriously but other times, they respond quickly to get it done. Overall there were low to moderate levels of motivation when completing evaluations and many did not pay attention to the wording of questions. Bassett and colleagues (2017) speculated that the reason why students were not motivated to fill in the forms fully was because they were doubtful that instructors used the CEQs.

Research has also found that what students want in a course are: high grades (Handelsman, Briggs, Sullivan, \& Towler, 2005); essays more than exams (Sander, Stevenson, King, \& Coates, 2000); limited writing (Krych-Appelbaum \& Musial, 2007); no presentations (Sander \& Sanders, 2005); and prompt feedback even if students do not incorporate that feedback into their work (Ackerman \& Gross, 2010). Ultimately, some studies conclude that students value "superficial learning that requires limited effort as opposed to courses with high achievement goals" (VanMaaren, Jaquett, \& Williams, 2016, p. 426). Jaquett, VanMaaren, and Williams (2017) suggest, based on the findings of their study, instructors can increase their student ratings by: allowing all students to get good grades; providing extra-credit options for all students; being organized; giving feedback promptly; not having small group discussions; limiting the inclusion of tests, course papers, and student presentations; and emphasizing the probability of student success rather than the commitment to high standards (VanMaaren et al., 2016, p. 436).

162 | LEARNing Landscapes | Spring 2020, Vol. 13 
Shifting from this focus on the micro level of student responses, we feel it is important to situate this type of assessment within the broader framework of neoliberalism and the attached audit culture. Neoliberalism as a dominant ideology of the twentieth-first century, insists that market forces and top-down hierarchies should be placed ahead of human moral agency and noneconomic forms of growth and value (Ross \& Gibson, 2007). Neoliberalism has been used as a value system to rationalize forms of governance that limit professional autonomy, increase surveillance, and force knowledge-workers in those industries to consistently do more for less. What academics are seeing is the systematic introduction of a set of governance practices developed in the worlds of business and public education that are being transplanted into public postsecondary institutions under the guise of efficiency-directed educational reforms. Much of this reform is taking place within a context that is ahistorical and nonsocial, with the only time horizons that matter are the compressed time horizons of fiscal emergencies and budget cuts. Singh (2018) describes the operation of these discursive and affective performative practices of control in the public schooling context, technologies that are also increasingly being put to work in the academic setting. As he notes, "these new 'datafication'...mechanisms firstly construct the 'teacher-as-problem' or barrier to quality learning, and then embed accountability/responsibility instruments into schools to fix the "teacher problem'" (p. 491).

We are well aware of the research on the problematic nature of CEQs both on the micro and macro levels. Yet, CEQs continue to be the single-most important evaluation tool for teaching effectiveness in our promotion and tenure process. In this paper, we want to explore what these tensions do to us and our teaching.

\section{Methodology}

We are early- to mid-career academics who work in a Faculty of Education in a midsized comprehensive university. Two of us (John and Cecile) are in adult/postsecondary education while Sarah works in the Faculty's counselling psychology program and educates future counsellors and teachers. We selected collaborative autoethnography as our methodology to explore our relationship to CEQs and how we believe these assessment instruments shape our teaching practice and identities (Chang, Ngunjiri, \& Hernandez, 2016). We began the project as co-participant-researchers with a collaborative discussion of the issues surrounding our experiences with CEQs. This first step in our method established the parameters of the data collection and determined how the individual aspect of data collection would be integrated into our methodology. The next step was to write individual autoethnographic narratives surrounding our experiences with CEQs. We purposefully gave space for creative writing and did not limit ourselves with the expectations of academic prose (Ellis, 2004). Finally, after the individual narratives were written, we gathered again as coresearchers for a collaborative discussion of the emerging issues associated with CEQs (the data analysis). In this final phase, we analyzed the autoethnographic narratives we had independently generated for themes and insights that would not only help us

understand our individual experiences, but also situate our experiences collectively in the context of the neoliberalism and current academic culture. Writing, telling, and sharing our stories became at once a 
means of exploring our awareness of social reality and of affirming the power and meaning of our own individual voices as an expression of our own agency as teachers and academics. Our collaborative autoethnographic analysis takes an evocative and provocative position in illuminating how the phenomenon of CEQs influence individual academics and the collective academy (students, faculty, and community). Collaborative autoethnography helped us to explore our perceptions and to understand the intersection of our experiences in ways which valued and respected individual subjectivities with shared meanings (Ingersoll, 2012).

\section{Assessment, Performativity, and Identity}

Our individual written narratives and collective reflection sessions on our experiences with CEQs revealed a number of central themes about how CEQs shaped the performance of our academic identities. Two of these themes were predominantly negative, namely the operation of CEQs as an anxiety-inducing intrusion into our everyday lives as teachers and scholars, and, their role in inducing us to perform conservative pedagogies. However, although CEQs forced us to confront the reality of neoliberalism's far-reaching intrusions into our institutions, they also reminded us of the importance of performing practices of resistance and sharing experiences as a means of creating a counter-discourse and spaces of renewal and hope.

\section{CEQs as Anxiety-Inducing Intrusions Into Everyday Life}

A central question of importance in today's educational politics, according to Ball (2003), is "who is it that determines what is to count as a valuable, effective or satisfactory performance and what measures or indicators are considered valid?" (p. 216). Increasingly, these determinations are not made by "us" (i.e., academics), but by managers and quality assurance systems that are imposed from beyond and above without discussion-increasing the alienation and frustration that has come to accompany so much of current academic life. They also lead to intensely personal and hidden conflicts, since these "struggles are often internalized and set the care of the self against duty to others" (p. 216), meaning that resistance often becomes characterized as selfishness or irresponsibility whereas compliance is associated with intrinsic moral worth.

Often our experiences are anxiety-ridden internalizations of the notion that we are potential problems in the making if we are not vigilant enough about our practice-it is almost as if we have to flap our wings frantically just to continually overcome the gravity of our own tendency towards mediocrity, or even, failure. As Cecile writes:

I see a brown envelope with a printed label in my mailbox. My heart drops. It's at least six weeks since I finished teaching. This can only be my course evaluation forms (CEQs). I take the envelope and leave it unopened on my desk, for days, sometimes for weeks, plucking up the courage to open it. 
John too noted seeing the CEQ envelope and leaving it unopened in his mailbox or on his desk for several days due to the anxiety it provokes, and to the possibility of receiving hurtful or frustrating comments from students. Like her colleagues, Sarah describes the seemingly impossible predicament that CEQs force us into:

The double bind as discussed by Gregory Bateson and his colleagues comes to mind. The doublebind is a no-win kind of communication. A classic example includes the message to be spontaneous; however...when following the directions to be spontaneous one is inherently not spontaneous. Another variation of the double-bind as when a person is chastised for a correct perception of the outside world. A classic example of this is when a child is in an abusive home and is yet expected to see the abusers as loving caregivers. In this scenario the child learns that they must choose to either trust their experiences or what others are telling them are truths. CEQs represent a variation of the double-blind. Faculty are told in several covert and overt ways that they have the knowledge and expertise to teach in their discipline and to interpret feedback from students accordingly; simultaneously they are told through the CEQ industry that students have the competency to evaluate their pedagogical expertise and are suitable evaluators for promotion and tenure in the academy. This following story is a good illustration of a double-bind and a solution:

A Zen master says to his pupils: "If you say this stick is real, I will beat you. If you say this stick is not real, I will beat you. If you say nothing, I will beat you." There seems to be no way out. One pupil, however, found a solution by changing the level of communication. He walked up to the teacher, grabbed the stick, and broke it. (Wedge, 2011, n.p.)

In applying the Zen story to CEQs, one option for faculty is to opt out of including CEQs in the promotion and tenure process and to dismiss these measures as anything other than student feedback on their experiences in the course. This feedback may then be considered in the larger course redevelopment process alongside other pedagogical variables rather than leading the course revision process. Opting out of including CEQs for promotion and tenure presents a more significant challenge in that faculty may face another double-bind. Colleagues sitting on the promotion and tenure committee may both consciously and unconsciously question why this faculty member chose not to include their CEQs in support of their teaching scholarship. CEQs have become so embedded and synonymous with evidence of teaching efficacy, even our peers may be skeptical about faculty teaching performance in the absence of CEQs. [Sarah]

As Sarah's narrative emphasizes, neoliberal assessment technologies force us to confront powerful institutional interests since they leave us with few or no alternatives. All of us felt pressured into dilemmas that were not of our own making and that did not seem to have any easy solutions. Although we wanted to continue to teach, write, and research in our own close-knit collegial communities, neoliberal regimes of power compel us to play these zero-sum games in a way that is intrusive, anxiety inducing, and often counterproductive. As we shall see, these types of misgivings often have a chilling effect on our own pedagogical engagement by limiting our sense of freedom and our willingness to explore.

\section{Performing Conservative Pedagogies and Limiting Academic Choice}

As one example of powerful, "academic performance management" technologies (Kenny, 2017, p. 900), CEQs shape our pedagogies in subtle, unexpected ways. CEQs presume and privilege a transactional model of teaching where "client" preferences are privileged above intellectual exploration and discovery. 
They entice us to perform a customer service mentality where professors are efficient knowledge workers who deliver services that customers are likely to want to consume. Collectively, neoliberal reforms and the audit culture that are its fundamental tools, have "reveal[ed] a worldwide trend of reduced self-determination of academics over key aspects of their work, a loss of influence over decision making about the allocation of resources within their institutions" (Kenny, 2018, p. 366). This may be something as simple as whether to use group work in one's courses:

My strengths and experience as an educator lie in designing curriculum for adult learning. Each course I have developed has been carefully crafted and scaffolded to bring students through the course with a minimum of disruption. I do, however, want to take them to new places, so often I ask them to engage in activities that are different but never without carefully creating conditions for learning. Group work is something I value and there is plenty of evidence and sound pedagogical reasons for including group work, particularly, in online learning. I use groupwork to reinforce learning, build skills and develop self-efficacy that can later be used in the bigger assignments. I ask students to complete short weekly group assignments based on the material for that week. Instead of just reading and discussing, I get students to apply that week's course material in a carefully constructed activity.

I often don't assign many marks for the groupwork activity because I want them to work under low-risk conditions and in most cases, unless a student did not complete an activity, they all get the entire mark allocated for the group activity. While there are many students in my classes who recognise and appreciate the pedagogic design and the role of group work, there are also many who do not. Every round of CEQs brings the inevitable barrage of comments around groupwork across my courses, despite the different iterations of groupwork, the carefully laid foundations, the meticulous organization and the many emails to ensure that everyone is on track...As one student noted "I'm not a fan of groupwork". Comments like these, make me first, grind my teeth in anger and then second, seek a darkened room to lie down in. I'm angry because these are really ill-informed opinions. I'm exhausted because the implication is that I must somehow make students "fans" of groupwork. Or I must remove groupwork to make their lives easier. [Cecile]

Although seen in isolation, CEQs may seem little more as a minor annoyance; when viewed in relation to broader systems of control, they become another piece of a surveillance apparatus that relies on appraising, quality control, and performative norms. We agree with Hennessy and McNamara (2013) who contend that, "within cultures of performativity, where knowledge is perceived as measurable and often explicitly defined, the propensity to question, challenge and critically evaluate knowledge is arguably limited" (p. 9). In classrooms that are dialogical and collaborative, these expectations inevitably influence how students construct their identities and, in turn, they play a role in shaping the classroom environment. As John wrote in his narrative:

CEQs affect me in two main ways I think. The first is that they make me less likely to be straightforward and honest with students. I feel like I have to be continually avoiding hurting their feelings or coming across as too demanding. Students today seem to feel like that if they are stressed or if they cannot understand something then it is automatically the instructor's fault. This is problematic for me as a teacher because in my view, if I am not challenging the assumptions of my students or challenging them then I am not doing my job. It is a delicate balance and one that becomes more worrisome when one is on the tenure track where there is so much scrutiny and it feels like any weaknesses or deficiency can be fatal. 
The other problematic way that CEQs impact me as an instructor is that they make me less likely to experiment with my teaching. You are more careful about trying anything out of the ordinary because you are not sure how students will react. Especially in an online environment when you try something new there are always wrinkles to iron out and this takes time. It is better to keep things relatively simple which I suppose might lead towards a kind of institutional group-think where everyone just tries to stay within the norms of expectations, at least until they get tenure and at that point they might not even care any longer about what happens. [John]

Where does this leave us? We cannot compel educational consumers to attend classes; we cannot make them uncomfortable with their privilege or the state of the environment. We are not supposed to challenge their abilities or to insist on the integrity of academic disciplines. We are creating a space where it is difficult, if not impossible, to be the teachers we want to be. For students, consumerism in higher education creates a type of pseudo-agency where market power stands in as a proxy for real critical consciousness and community-building. This is particularly true for academics who lack the protection of institutional tenure:

Early career scholars and untenured faculty are dependent upon CEQs to demonstrate their teaching efficacy, this however is an impossible task as the CEQ does not measure the quality of instruction, does not account for pedagogical choices, and does not consider the power relationships between students and faculty. In fact, CEQs act upon early career scholars and untenured faculty in an oppressive manner, forcing them to choose: do I teach for a positive CEQ outcome or do I teach to unsettle, to disrupt and to challenge learners. A dichotomous relationship of performance is established when faculty must choose, do I perform the act of educator for the promotion and tenure committee, or do I perform the act of educator for the learners in my class. [Sarah]

Neoliberal scripts are hidden, but they are revealed in the practices and habits that shape our everyday existence, especially when they are presented as inevitable or without any realistic alternatives; they shape our sense of self, our capacity for self-determination, and our desires (Clarke, 2013). Questioning CEQs and other aspects of audit-culture does not mean that one is against good teaching, or that one does not care about students. We need to collaborate with students and our peers to try and find meaningful alternatives that allow us to perform our identities in more fulfilling and empowering ways. We find a sense of kinship and shared purpose by

'giving voice' in the manner in which we have done so is an effective means of "talking back" against such neo-liberal regimes of performativity which may also be effective as a form of localized resistance, strengthening our ability to cope with the anxiety such regimes routinely provoke. (Ruth, Wilson, Alakavuklar, \& Dickson, 2018, p. 154)

\section{CEQs Remind Us of the Importance of Performing Resistance}

What the CEQ process reveals is an underlying message that flaws are not an expected part of a unique human identity, but are a kind of pathology that need to be quarantined or expelled. Such a norm conditions us to hide our vulnerabilities, and to avoid those who are open and honest enough to give voice to their own. The pursuit of knowledge and truth does not extend to self-knowledge or psychological truth; these things are not of interest to tenure and promotion committees or external 
referees, though they do exist, like a kind of growing collective subconscious that needs to be continually repressed even as it finds other means of expression—some destructive and, we hope, others that gesture towards happier endings. In order to "count" you have to become another self, even as your other hidden self comes to cease to exist. We have to hide the self that we want to exist. Sometimes, even just acknowledging and sharing one's own frustration can lead to seeing the possibility of opting out of seemingly all-pervasive governance practices:

The group work I design forces students to 1) engage in course material by having to apply what they learned that week; 2) communicate with other learners. I do this because we have so many online learners who don't even read the course content and only submit the assignments. My courses make them work. The question I ask myself before teaching this semester was: What should I do, based on these CEQ comments? Should I give up on group work because students aren't "fans"? Like I gave up on the digital essay I asked students to produce one year, or the co-operative app that I asked students to use another year to read a paper together? Anything new and different is too much work, too complicated, not worth the marks. Should I leave students to work in isolation - something that I know will not aid learning or enrich their experience? The educator in me refuses to give up on group work. A more satisfying solution would be not to open that brown envelope when it turns up in my mailbox. [Cecile]

Imagining otherwise, even giving voice to our sense of frustration, is not a meaningless exercise but a means of finding alternative tactics of resistance, such as, for example, "insisting that a diverse range of meanings be ascribed to a term like 'quality' rather than allowing it to be reduced to the results of high-stakes test scores" (Clarke, 2013, p. 236). John has similar worries about the impact of CEQs on the teacher-student relationship:

All in all, although I can understand the rationale for CEQs I think that they can become a substitute for a deeper relationship with students and an academic environment that is an intense and vibrant community. Instead they have become a one size fits all solution to a problem that is really about true caring and the need for both students and teachers to be present in a world where we are increasingly frustrated, unappreciated, and alone. Why isn't there some similar measure for administrators or students themselves I wonder? Or a better way to take an inventory of our feelings? These types of transactional quick fixes are a poor substitute for real meaningful conversations about the nature and purpose of education and how we can work together to create more meaningful and authentic educational experiences. Maybe there should be a box we can all check for that? Sign me up. I'm all in for that. [John]

Those researchers who work in autoethnography and self-study understand the powerful synergies that can result from careful study of the institutional subject roles and the spaces of resistance that are open to being reclaimed. Rather than pitting us against students and each other, scholars and students need to re-signify the meaning and nature of the university that is more than a conglomeration of inputs, outputs, and efficient processes, but rather, a community that is critical, rooted in meaningful institutional practices and that is firmly committed to the nature of education as a critical public good. Autoethnography in the neoliberal academy becomes a counter-trend in a world where "concerted focus on measurement and testing in education has also resulted in the emergence of an affective/effective divide in which attention to the affective is perceived to exist at the expense of effectiveness in education" 
(Hennessy \& McNamara, 2013, p. 10). Sarah describes a one-on-one assessment session that she had as a graduate student that was both difficult and transformative:

My heart began to race, the heat from inside was slowly moving its way up toward my fleshy cheeks, a thought flashes in, why do I have to show the intensity of my feelings on my face so clearly. It's like a direction or sign post to everyone "something is wrong" I'm not ready for them to know yet how angry I am, how embarrassed I am honestly. 12 other students are sitting quietly, as we all receive our first year performance evaluations. Objectively I should be pleased, the narrative reports of my academic and clinical performance sing high praise, I however have tunnel vision for the last small paragraph.

"Sarah is passionate and a staunch advocate for social justice. She raises important conversations with her peers and professors, conversation that may cause us to pause and critically engage with issues of equity which she offers up for dialogue, however her approach is off-putting and we are concerned about her apparent difficulty regulating her emotions, anger in particular in these instances. The manner in which she approaches others can be abrasive, demanding and results in disengagement and verges at time on unprofessional behavior."

In one fell swoop I was enraged and terrified, overwhelmed. What would this mean for me as a professional? Is this really how I am perceived? How was it possible that my intentions were experienced by others in this way? [Sarah]

As Sarah reflects on this encounter today, she realized how important it was for her to experience and process these powerful emotions:

I paused before acting. Time seemed to have stopped, it was in slow motion. I took a deep breath. I had a choice. It was an importance decision in that moment, at 28 in entering my second year of a clinical psychology doctoral program, I could choose to accept the information I was presented with or reject it...I chose acceptance. In the years since this moment I have come to a nuanced understanding of how privilege, mediates the feedback I received from my now colleagues.

How does this relate to evaluation, assessment and critical review?

You see while the information I received was challenging to integrate I could not disregard it. As a student I was compelled to engage with this narrative feedback. It had meaning because it was catered to me as a learner. Upon entering the academy several years later, I naïvely assumed that is the same ethic as care, flaws and all, which I had experienced as a student with evaluation would be reciprocated in the evaluation process for faculty. Instead I found the CEQ measures to be unhelpful, dismissive of my expertise as an educator and scholar and an invalidating process for both students and faculty. [Sarah]

As the above narrative demonstrates, performativity as a means of continually writing and rewriting the self, cuts both ways. It can be a technique of consciousness raising as well as a neoliberal technology of control. If teaching is a meaningful part of academic freedom and our teaching identities are constructed by quality assurance instruments like CEQs then, we need to focus our attention on the centrality of identity and identity-shaping practices as being fundamental to intellectual activity and freedom of inquiry. 
John L. Hoben, Cecile Badenhorst, and Sarah Pickett

\section{Performing Otherwise-Concluding Thoughts}

What do CEQs do to our teaching and to our perceptions of ourselves as teachers? We were surprised at the extent of our frustration and anger with an institutional practice that has become ubiquitous. We draw three conclusions from the exploration of our experiences: First, the presumption with CEQs is that we need to continually be proving our worth as university teachers. Despite qualifications, long-term experience, and in-depth knowledge, we are positioned as the "problem" and need to continually prove that we can do our jobs. This is particularly relevant for those of us in Education. Second, what our narratives show is that CEQs are a micro theme within the bigger picture of a service delivery model of university teaching. CEQs function as a means of undermining teachers' status and autonomy by positioning them as neoliberal knowledge workers who need to adopt a customer-service type of mentality rather than seeing students as community-members who share responsibility. While we focus our struggles on the micro (CEQs), the macro situation becomes invisible. CEQs become yet another administrative task in an increasingly long list of matters to negotiate. CEQs also reinforce notions of individualization since it is the individual who carries the responsibility of teaching in the university. With this individualization comes shame-if the CEQ results are poor-and isolation. The final point we would like to make is that engaging with CEQs collectively as we have done in this paper, shifts us away from a blame-culture and fosters individual shame resilience. In this collective space, it is easier to move towards useful conversations of teaching accountability and a resistance of CEQs.

\section{References}

Ackerman, D. S., \& Gross, B. L. (2010). Instructor feedback: How much do students really want? Journal of Marketing Education, 32, 172-181.

Adams, M. J. D., \& Umbach, P. D. (2012). Nonresponse and online student evaluations of teaching: Understanding the influence of salience, fatigue, and academic environments. Research in Higher Education, 53(5), 576-591.

Ball, S. (2003). The teacher's soul and the terrors of performativity. Journal of Education Policy, 18(2), 215-228.

Bassett, J., Cleveland, A., Acorn, D., Nix, M., \& Snyder, T. (2017). Are they paying attention? Students' lack of motivation and attention potentially threaten the utility of course evaluations. Assessment \& Evaluation in Higher Education, 42(3), 431-442.

Butler, J. (1997). The psychic life of power. Theories in subjection. Stanford University Press.

Chang, H., Ngunjiri, F., \& Hernandez, K. A. C. (2016). Collaborative autoethnography. Routledge.

Clarke, M. (2013). Terror/enjoyment: Performativity, resistance and the teacher's psyche.

London Review of Education, 11(3), 229-238.

Ellis, C. (2004). The ethnographic I: A methodological novel about autoethnography. Altamira. 
Groen, J. F., \& Herry, Y. (2017). The online evaluation of courses: Impact on participation rates and evaluation scores. Canadian Journal of Higher Education/Revue canadienne d'enseignement supérieur, 47(2), 106-120.

Handelsman, M., Briggs, W., Sullivan, N., \& Towler, A. (2005). A measure of college student course engagement. The Journal of Educational Research, 98, 184-192.

Hennessy, J., \& McNamara, P. (2013). At the altar of educational efficiency: Performativity and the role of the teacher. English Teaching: Practice and Critique, 12(1), 6-22.

Ingersoll, M. (2012). Narrative insights: A creative space for learning. LEARNing Landscapes, 6(1), 215-221.

Jaquette, C. M., VanMaaren, V. G., \& Williams, R. L. (2017). Course factors that motivate student to submit end-of-course evaluations. Innovation in Higher Education, 42, 19-31. doi:10.1007/s10755016-9368-5.

Kenny, J. (2017). Academic work and performativity. Higher Education, 74(5), 897-913. Retrieved from http://dx.doi.org.qe2a-proxy.mun.ca/10.1007/s10734-016-0084-y

Kenny, J. (2018). Re-empowering academics in a corporate culture: An exploration of workload and performativity in a university. Higher Education, 75(2), 365-380. Retrieved from http://dx.doi.org.qe2aproxy.mun.ca/10.1007/s10734-017-0143-z

Krych-Appelbaum, M., \& Musial, J. (2007). Students' perception of value of interactive oral communication as part of writing course papers. Journal of Instructional Psychology, 34, 131-136.

MacNell, L., Driscoll, A., \& Hunt, A. N. (2015). What's in a name? Exposing gender bias in student ratings of teaching. Innovative Higher Education, 40, 291-303. doi:10.1007/s10755-014-9313-4

Maurer, T. W. (2006). Cognitive dissonance or revenge? Student grades and course evaluations. Teaching of Psychology, 33, 176-179.

Ross, E. W., \& Gibson, R. (Eds.) (2007). Neoliberalism and education reform. Hampton Press.

Ruth, D., Wilson, S., Alakavuklar, O., \& Dickson, A. (2018). Anxious academics: Talking back to the audit culture through collegial, critical and creative autoethnography. Culture and Organization, 24(2), 154-170.

Sander, P., \& Sanders, L. (2005). Students' presentations: Does the experience change their views? Psychology Teaching Review, 11, 25-41.

Sander, P., Stevenson, K., King, M., \& Coates, D. (2000). University students' expectations of teaching. Studies in Higher Education, 25, 309-323.

Singh, P. (2018). Performativity, affectivity and pedagogic identities. European Educational Research Journal, 17(4), 489-506.

VanMaaren, V. G., Jaquett, C. M., \& Williams, R. L. (2016). Factors most likely to contribute to positive course evaluations. Innovations in Higher Education, 41, 425-440.

Wedge, M. (2011). The double binds of everyday life. Psychology Today. Retrieved from: https://www.psychologytoday.com/ca/blog/suffer-the-children/201110/the-double-binds-everyday-life 
Winer, L., DiGenova, L., Costopoulos, A., \& Cardoso, K. (2016). Addressing common concerns about online student ratings of instruction: A research-informed approach. Canadian Journal of Higher Education/Revue canadienne d'enseignement supérieur, 46(4), 115-131.

Zumbach, J., \& Funke. J. (2014). Influences of Mood on Academic Course Evaluations. Practical Assessment, Research \& Evaluation, 19(4), 1-12. Retrieved from http://pareonline.net/getvn/getvn.asp? $v=19 \& n=4$.

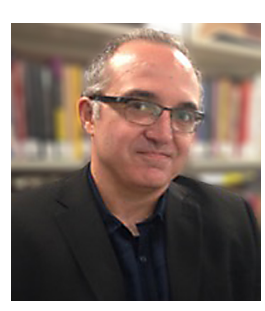

John L. Hoben is an Assistant Professor in Memorial's Faculty of Education with an LLB from the University of Western Ontario and a PhD from Memorial University of Newfoundland. A nonpracticing lawyer, in 2007 he was awarded a SSHRC Canada Graduate Scholarship (Doctoral) to conduct a study of teacher free speech, which formed the basis for his recent book on teacher speech in Canada and the United States. John's areas of expertise include postsecondary education, fundamental rights and freedoms, the sociology of law, and democratic education.

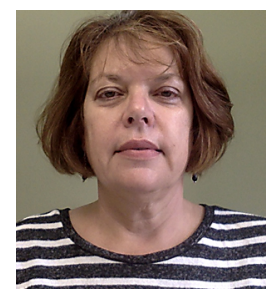

Cecile Badenhorst, MA (UBC), PhD (Queen's), is an Associate Professor in the Adult Education/Post-Secondary program in the Faculty of Education at Memorial University of Newfoundland. She teaches courses in the postsecondary undergraduate and graduate programs on university teaching and learning, as well as courses in the Faculty's doctoral program. As a researcher, she has conducted research and published in the areas of doctoral education, doctoral writing, graduate writing, thesis/publication writing pedagogies, academic literacies, and faculty writing. She engages in qualitative, arts-based, and post-structural research methodologies.

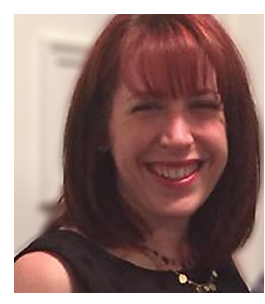

Sarah R. Pickett is an Associate Professor in the Faculty of Education at Memorial University of Newfoundland and a Registered Psychologist. Her research focuses on affirmative sexuality and gender practice and pedagogy in education and healthcare. Dr. Pickett is interested in narrative and autoethnographic methodologies; how researchers may use these methods to engage in evocative conversations in educational contexts and actively publishes in this area from the position of parent, lesbian/queer, psychologist, educator of educators, counselor educator, and academic. 